\title{
Effect of Pediatric Testicular Torsion on Testicular Function in the Short Term
}

\section{Taskinen, Seppo}

2020-08

Taskinen , S , Mäkelä , E \& Raivio , T 2020 , ' Effect of Pediatric Testicular Torsion on

Testicular Function in the Short Term ', Journal of Pediatric Surgery , vol. 55 , no. 8 , pp.

1613-1615 . https://doi.org/10.1016/j.jpedsurg.2019.10.023

http://hdl.handle.net/10138/333731

https://doi.org/10.1016/j.jpedsurg.2019.10.023

draft

Downloaded from Helda, University of Helsinki institutional repository.

This is an electronic reprint of the original article.

This reprint may differ from the original in pagination and typographic detail.

Please cite the original version. 


\title{
Effect of Pediatric Testicular Torsion on Testicular Function in the Short Term
}

\author{
Seppo Taskinen a,*, Eija Mäkelä a, Taneli Raivio ${ }^{\text {b,c }}$ \\ a Department of Pediatric Surgery, Helsinki, Finland \\ b Pediatric Research Center New Children's Hospital, Helsinki University Hospital, Helsinki, Finland \\ c Department of Physiology, Medicum Unit, and Translational Stem Cell Biology and Metabolism Research Program, Faculty of Medicine, University of Helsinki, Helsinki, Finland
}

\section{A R T I C L E I N F O}

\section{Article history:}

Received 1 June 2019

Received in revised form 20 August 2019

Accepted 5 October 2019

Available online $\mathrm{xxxx}$

\section{Key words:}

Testis

Testicular torsion

FSH

Inhibin B

Fertility

\begin{abstract}
A B S T R A C T
Purpose: To evaluate short-term testicular outcome after torsion in children.

Methods: Fifty-four children and adolescents were evaluated after 6 months of the operation for testicular torsion. Testicular volume was measured and circulating Inhibin B, FSH, LH and testosterone levels were checked. Results: Delay from the onset of symptoms to surgery was shorter in the orchidopexy group $(n=47)$, than in the orchiectomy group $(n=7, \mathrm{p}=0.001)$. In the orchidopexy group, the median volume of the affected testis was 83\% (IQR 43-104) of the contralateral testis $(\mathrm{p}=0.002)$. The plasma hormone levels in orchidopexy and orchiectomy groups were: $148 \mathrm{ng} / \mathrm{l}(\mathrm{IQR} 108-208) v s .129 \mathrm{ng} / \mathrm{l}(\mathrm{IQR}, 123-138, \mathrm{p}=0.269)$ for Inhibin $\mathrm{B} ; 4.5 \mathrm{IU} / \mathrm{L}$ (IQR2.6-6.9) vs. $11.7 \mathrm{IU} / \mathrm{L}(\mathrm{IQR} 4.3-12.8, \mathrm{p}=0.037)$ for FSH; $2.9 \mathrm{IU} / \mathrm{L}(\mathrm{IQR} 1.3-3.7)$ vs. 4.8 (IQR 3.0-5.6, $\mathrm{p}=$ 0.066 ) for $\mathrm{LH}$; and $13.6 \mathrm{nM}$ (IQR 6.5-18.0) vs. $14.5 \mathrm{nM}$ (IQR 6.7-15.9, $\mathrm{p}=0.834$ ) for testosterone. The association between FSH, $\mathrm{LH}$ as well as testosterone levels was most clear with the volume of the contralateral testis ( Rho = $0.574, \mathrm{p}<0.001$, Rho $=0.621, \mathrm{p}=0.001$ and Rho $0.718, \mathrm{p}<0.001$ respectively).

Conclusions: Testicular function is mainly dependent on the volume of contralateral testicle after testicular torsion. However, testis preserving surgery tends to maintain better function than orchiectomy.

Type of study: Retrospective review.

Level of evidence: III
\end{abstract}

(c) 2019 Elsevier Inc. All rights reserved.
Testicular torsion can lead to testicular damage and even to complete necrosis of the testis. Fortunately, testicular torsion is a rare event with an annual incidence of 4.5/ 100,000 in males aged 1-25 years [1,2]. The effect of unilateral torsion on total testicular function is apparently rather small, but, in some cases, the function may be compromised [3-5]. The suggested reasons have been ischemia-reperfusion injury and testicular dysplasia as well as loss of testicular cells [4,6-8].

Some studies have suggested that preserving surgery of the affected testis may be even more harmful to the contralateral testis than orchiectomy [7]. Consequently, the threshold to do orchiectomy may wary between the different centers. In our previous pilot study with children and adolescents, there was a tendency towards better testicular function, if the twisted testis was preserved [8]. Accordingly we have selected the line to avoid orchiectomy unless the twisted testis is clearly necrotic.

In this study, we expanded our original pilot study, in an attempt to evaluate whether an active approach to preserve the twisted testis

Declarations of interest: none.

* Corresponding author at: New Children's Hospital, Helsinki University Hospital, Stenbäckinkatu 9, 00290 Helsinki, Finland. Tel.: + 358504272542.

E-mail address: seppo.taskinen@hus.fi (S. Taskinen). appears justified [8]. Testicular function was evaluated with hormonal measurements primarily reflecting the function of seminiferous epithelium (FSH and Inhibin B) or testosterone production ( $\mathrm{LH}$ and testosterone), and testicular size was measured with ultrasound.

\section{Material and methods}

Fifty-four patients operated between 2000 and 2018 for testicular torsion and followed in the division of pediatric urology were evaluated after the institutional Ethics Committee had approved the study based on a retrospective chart review. Testicular volume and serum Inhibin $\mathrm{B}, \mathrm{FSH}, \mathrm{LH}$ and testosterone levels were measured six months (range 5-18) after the surgery. Five patients who fulfilled the criteria were included from our previous study [8]. After that, 49 consecutive patients were included. However, 14 patients were excluded because of insufficient follow-up investigations (testicular volume measurements and InhibinB as well as FSH values missing or too short follow-up time, $n=11$ ) or because the patient had moved to other district $(n=3)$.

The age of the patient, the duration of symptoms and the type of the operation were recorded. Twisted testicle was removed if the black color did not change after untwisting and no fresh bleeding appeared after small incision to testicle. Testicular volume was 
measured in 47 patients with ultrasound and in four patients with a ruler applying ellipsoid formula $(a \times b \times c \times 0.52)$. Serum Inhibin B, FSH, LH and testosterone values were measured in 50, 51, 46 and 50 patients respectively. Normal laboratory values for FSH and LH were for age group 2-5 years, $0.2-1.4 \mathrm{IU} / \mathrm{l}$ and $0-0.5 \mathrm{IU} / \mathrm{l}$; age group $6-10$ years, $0.2-1.4 \mathrm{IU} / \mathrm{l}$ and $0-0.5 \mathrm{IU} / \mathrm{l}$; and age group $11-20$ years, $0.2-8 \mathrm{IU} / \mathrm{l}$ and 0.5-5.3 IU/1 respectively. For testosterone, normal values were $0.1-1.1 \mathrm{nmol} / \mathrm{l}$ for pre pubertal, $0.4-2 \mathrm{nmol} / \mathrm{l}$ in Tanner stage $2-3$ and $10-23 \mathrm{nmol} / \mathrm{l}$ for adult males.

\subsection{Statistical analysis}

The association between testicular volume and the delay of surgery from the onset of symptoms as well as association with hormonal values was evaluated with Spearman rank correlation. The differences of volumes between twisted and contralateral testis were evaluated with Wilcoxon signed rank test. Categorical values were compared with Fisher's exact test. Continuous variables are expressed as medians and interquartile ranges (IQR) or ranges. For the analyses Statview ${ }^{\circledR}$ 5.0.1, SAS Institute Inc. was used. P-value $<0.05$ was considered significant.

\section{Results}

\subsection{Testicular volume}

Testicular torsion occurred on the left side in 28 of 54 cases (52\%) and it was operated at the median age of 14 years (IQR 12.8-14.5, range $1.8-16.3, \mathrm{p}=0.817$ between orchidopexy $(n=46)$ and orchiectomy ( $n=7$ ) groups). Delay from the onset of symptoms to surgery was $6 \mathrm{~h}$ (IQR 4-13) in the orchidopexy group, and $48 \mathrm{~h}$ (IQR 30-72) in the orchiectomy group ( $\mathrm{p}=0.001)$. In the orchidopexy group, the median volume of the twisted testis was $83 \%$ (IQR 43-104) of the contralateral testis at follow-up ( $\mathrm{p}=0.002)$, and the time in the delay of the operation and the degree of relative volume reduction were associated (Rho $-0.676, \mathrm{p}<0.001$, Fig. 1 )). In five cases, the preserved twisted testis became atrophic (volume less than $20 \%$ of the contralateral testes). In those cases, the delay of surgery was in median $72 \mathrm{~h}$ (range 20-168).

\subsection{Hormonal values}

Serum FSH values were lower in patients after testis preserving surgery than after orchiectomy (Table 1 ). In LH values, there was a similar but nonsignificant tendency. Age-specific FSH values were altogether abnormal in 4/7 patients in the orchiectomy group and in 5/45 patients in the orchidopexy group $(\mathrm{p}=0.013)$.

Serum FSH, LH and testosterone levels associated with total testicular volume ( $p=0.026,0.001$ and $<0.001$ respectively) and

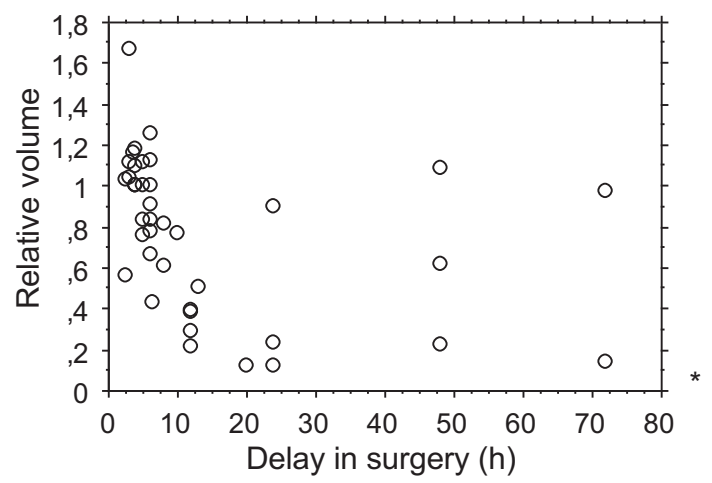

Fig. 1. Time from the onset of symptoms to surgery and the volume of twisted testicle in relation to contralateral testicle after half a year. ${ }^{*}$ The relative volume of twisted testis was 0.02 in one patient with $168 \mathrm{~h}$ delay in surgery.
Table 1

Serum hormone levels half a year after testicular torsion.

\begin{tabular}{|c|c|c|c|c|c|}
\hline & \multicolumn{2}{|c|}{ Orchidopexy $(n=47)$} & \multicolumn{2}{|c|}{ Orchiectomy $(n=7)$} & \multirow[t]{2}{*}{ p-value } \\
\hline & $n$ & value & $n$ & value & \\
\hline Inhibin B (ng/L) & 44 & 148 (IQR 108-208) & 6 & 129 (IQR 123-138) & 0.269 \\
\hline FSH (IU/L) & 44 & 4.5 (IQR 2.6-6.9) & 7 & 11.7 (IQR 4.3-12.8) & 0.037 \\
\hline $\mathrm{LH}(\mathrm{IU} / \mathrm{L})$ & 41 & 2.9 (IQR 1.3-3.7) & 5 & 4.8 (IQR 3.0-5.6) & 0.066 \\
\hline $\begin{array}{l}\text { Testosterone } \\
(\mathrm{nmol} / \mathrm{l})\end{array}$ & 44 & 13.6 (IQR 6.5-18.0) & 6 & 14.5 (IQR 6.7-15.9) & 0.834 \\
\hline
\end{tabular}

especially with the volume of the contralateral testis ( $p<0.001$ for all) in the patients who had undergone testicular preserving surgery (Table 2). Testosterone and LH levels associated also with the volume of the twisted testis ( $p=0.009$ and 0.001 respectively). In the patients with testicular sparing surgery, the degree of relative shrinking in affected testis was not associated with serum Inhibin B, FSH, LH or testosterone values ( $p>0.2$ for all). The result suggests that Sertoli cell function is mainly dependent on the volume of contralateral testis, but apparently, the twisted testis has some influence on testosterone production.

\section{Discussion}

In this study, testicular size and function were investigated about six months after surgery for testicular torsion. The time from the onset of symptoms to surgery was longer in the patients who underwent orchiectomy compared with the patients having testicular sparing surgery. In addition, the time between the onset of symptoms and surgery and the relative atrophy rate of the twisted testis to the contralateral testis were associated in the testicular-preserving surgery group. Sertoli cell function according to serum FSH levels was mainly associated with the volume of contralateral testis. However, the function was somewhat better in the patients with testicular-preserving surgery. Also, testosterone production associated strongly with the volume of contralateral testis. However, there was also a significant association between the relative volume of the twisted testis and Leydig cell function. We could not find any evidence for harmful effect as a result of damaged testis left in place after detorsion and orchidopexy.

In our study, the rate of severe testicular damage was 12/54 (22\%) when calculating together orchiectomy cases and cases with later atrophy of the affected testis. In previous studies, testicular torsion leads usually to orchiectomy or testicular atrophy in 30-67\% of cases [1,9-11]. In a recent study, all the twisted testicles were spared and 11 out of 30 testicles underwent at least $80 \%$ volume loss during the median follow-up of 111 days [10]. Duration of symptoms before the surgery has been one of the most important factors dictating the fate of the testis in our and in previous studies [10,12]. Symptom history longer than $6 \mathrm{~h}$ prior to surgery can lead to some degree of volume reduction, but after $24 \mathrm{~h}$, the twisted testis rarely survives [10,12]. Although a delay in the treatment from the onset of symptoms usually leads to loss of the

Table 2

Spearman correlation between testicular volumes and serum hormonal levels in patients with testicular preserving surgery half year after testicular torsion.

\begin{tabular}{|c|c|c|c|c|c|c|}
\hline & \multicolumn{2}{|c|}{$\begin{array}{l}\text { Volume of } \\
\text { contralateral } \\
\text { testis }\end{array}$} & \multicolumn{2}{|c|}{$\begin{array}{l}\text { Volume of } \\
\text { twisted testis }\end{array}$} & \multicolumn{2}{|c|}{$\begin{array}{l}\text { Total testicular } \\
\text { volume }\end{array}$} \\
\hline & Rho & p-value & Rho & p-value & Rho & p-value \\
\hline Inhibin B & 0.207 & 0.185 & 0.244 & 0.118 & 0.291 & 0.063 \\
\hline FSH & 0.574 & $<0.001$ & 0.329 & 0.293 & 0.348 & 0.026 \\
\hline LH & 0.621 & $<0.001$ & 0.427 & 0.009 & 0.532 & 0.001 \\
\hline Testosterone & 0.718 & $<0.001$ & 0.502 & 0.001 & 0.658 & $<0.001$ \\
\hline
\end{tabular}


testicle, it does not mean that the patients with long-lasting symptoms are not in the need of urgent treatment. In our study, one testis maintained normal volume despite of symptoms lasting for $96 \mathrm{~h}$. Apparently, in clinical situations, testicular twisting does not necessarily lead to immediate loss of circulation, and at least the cases with sudden progression of symptoms must be considered for urgent treatment.

In this study, 9/52 patients (17\%) had abnormal FSH values and the risk was increased in those who had undergone orchiectomy. FSH and Inhibin B measurements have turned out to be useful in the determination of the fertility potential [13-17]. In this study, FSH, LH and testosterone values associated best with the volume of the contralateral testis. Some association existed also between the volume of affected testis and LH as well as testosterone values. Similarly in the study evaluating hormonal profiles in monorchid boys, the Sertoli cell function was worse in the patients than in the controls with two testicles [18]. However, in that study there was no apparent difference in the function of Leydig cells. In experimental models, the twisted testis has been observed to lose germ cell population more often than Sertoli and Leydig cells [19]. In our study, atrophied testis was not causing negative impact on testicular function according to reproductive hormonal values. In previous studies with semen analyses, the results have been contradictory showing decreased or normal sperm counts after unilateral torsion $[4,20]$. In the study of Romeo et al., serum Inhibin B levels were reduced in the patients who had testicular torsion on average 5 years earlier compared to controls [21]. In that study, no difference was observed between those who had undergone testis preserving surgery or orchiectomy. However, in the Chinese study, all 86 patients had normal FSH levels at follow-up both in orchiectomy and orchidopexy groups [22]. In the study by Anderson et al. the, the sperm quality of 16 patients was better in orchiopexy than in orchiectomy group [23]. However, in the study by Arap, the sperm count and presence of antisperm antibodies of 24 patients were similar in both groups but the motility was better in in the orchiectomy group [20].

Our study has limitations. There was some variation in the follow-up times although they were scheduled to be 6 months afterwards. In some cases, not all the scheduled investigations were realized. However, the follow-up appointment was at least five months after surgery, and in our clinical experience, it is a sufficient time for the development of testicular atrophy. There was variation in patients' ages, and unfortunately, the pubertal status was not recorded. However, we used age-specific reference values and the volumes of the twisted testes were compared with the contralateral ones in the same patients. The orchiectomy rate in our study was small for comparisons, but, on the other hand, orchiopexy results were in the favor for testicular salvage.

\section{Conclusions}

In this study, we found out that the larger the total testicular volume, the better the testicular function appeared to be after testicular torsion. Sertoli cell function appeared mainly dependent on the volume of the contralateral testis, and it seems that, in doubtful cases, it may be better to preserve the affected testis than to remove it.

\section{References}

[1] Cost NG, Bush NC, Barber TD, et al. Pediatric testicular torsion: demographics of national orchiopexy versus orchiectomy rates. J Urol 2011;185:2459-63. https://doi. org/10.1016/j.juro.2011.01.016.

[2] Molokwu CN, Somani BK, Goodman CM. Outcomes of scrotal exploration for acute scrotal pain suspicious of testicular torsion: a consecutive case series of 173 patients. BJU Int 2011;107:990-3. https://doi.org/10.1111/j.1464-410X. 2010.09557.

[3] Schütte B, Becker H, Vydra G. Exocrine and endocrine testicular function following unilateral torsion-a retrospective clinical study of 36 patients. Urologe A 1986;25: 142-6.

[4] Visser AJ, Heyns CF. Testicular function after torsion of the spermatic cord. BJU Int 2003;92:200-3.

[5] DaJusta DG, Granberg CF, Villanueva C, et al. Contemporary review of testicular torsion: new concepts, emerging technologies and potential therapeutics. J Pediatr Urol 2013;9:723-30. https://doi.org/10.1016/j.jpurol.2012.08.012.

[6] Hagen P, Buchholz MM, Eigenmann J, et al. Testicular dysplasia causing disturbance of spermiogenesis in patients with unilateral torsion of the testis. Urol Int 1992;49: 154-7.

[7] Filho DW, Torres MA, Bordin AL, et al. Spermatic cord torsion, reactive oxygen and nitrogen species and ischemia-reperfusion injury. Molec Asp Med 2004;25: 199-210.

[8] Taskinen S, Taskinen M, Rintala R. Testicular torsion: orchiectomy or orchiopexy? J Pediatr Urol 2008;4:210-3. https://doi.org/10.1016/j.jpurol.2007.11.007.

[9] Mansbach JM, Forbes P, Peters C. Testicular torsion and risk factors for orchiectomy. Arch Pediatr Adol Med 2005;159:1167-71.

[10] Grimsby GM, Schlomer BJ, Menon VS, et al. Prospective evaluation of predictors of testis atrophy after surgery for testis torsion in children. Urology 2018;116:150-5. https://doi.org/10.1016/j.urology.2018.03.009.

[11] MacDonald C, Kronfli R, Carachi R, et al. A systematic review and meta-analysis revealing realistic outcomes following paediatric torsion of testes. J Pediatr Urol 2018;14:503-9. https://doi.org/10.1016/j.jpurol.2018.09.017.

[12] Mellick LB, Sinex JE, Gibson RW, Mears K. A Systematic review of testicle survival time after a torsion event. Pediatr Emerg Care 2017 Sep 25. doi: 10.1097/PEC. 0000000000001287. Epub ahead of print]10.1097/PEC.0000000000001287. Epub ahead of print]

[13] Raivio T, Saukkonen S, Jääskeläinen J, et al. Signaling between the pituitary gland and the testes: inverse relationship between serum FSH and inhibin concentrations in boys in early puberty. Eur J Endocrinol 2000;142:150-6.

[14] Kojima Y, Hayashi Y, Mizuno K, et al. Assessment of serum folliclestimulating hormone level and testicular volume for prediction of paternity potential in pubertal boys who underwent bilateral orchiopexy in childhood. J Urol 2006;175:2290-4.

[15] Zitzmann M, Nordhoff V, von Schönfeld V, et al. Elevated follicle-stimulating hormone levels and the chances for azoospermic men to become fathers after retrieval of elongated spermatids from cryopreserved testicular tissue. Fertil Steril 2006;86: 339-47.

[16] Cortes D, Thorup J, Hogdall E, et al. The relation of germ cells per tubule in testes, serum inhibin B and FSH in cryptorchid boys. Pediatr Surg Int 2007;23:163-9.

[17] Trsinar B, Muravec UR. Fertility potential after unilateral and bilateral orchidopexy for cryptorchidism. World J Urol 2009;27:513-9. https://doi.org/10.1007/s00345009-0406-0.

[18] Grinspon RP, Habib C, Bedecarrás P, et al. Compensatory function of the remaining testis is dissociated in boys and adolescents with monorchidism. Eur J Endocrinol 2016;174:399-407. https://doi.org/10.1530/EJE-15-0938.

[19] Karaguzel E, Kadihasanoglu M, Kutlu O. Mechanisms of testicular torsion and potential protective agents. Nat Rev Urol 2014;11:391-9. https://doi.org/10.1038/nrurol. 2014.135.

[20] Arap MA, Vicentini FC, Cocuzza M, et al. Late hormonal levels, semen parameters, and presence of antisperm antibodies in patients treated for testicular torsion. J Androl 2007;28:528-32.

[21] Romeo C, Impellizzeri P, Arrigo T, et al. Late hormonal function after testicular torsion. J Pediatr Surg 2010;45:411-3. https://doi.org/10.1016/j.jpedsurg.2009.10.086.

[22] Yang C, Song B, Tan J, et al. Testicular torsion in children: a 20-year retrospective study in a single institution. ScientificWorldJournal 2011;11:362-8. https://doi. org/10.1100/tsw.2011.39

[23] Anderson JB, Williamson RCN. Testicular torsion in Bristol: a 25 year review. Br J Surg 1988;75:988-92. 